\title{
Isabel Cranz
}

\section{Atonement and Purification}

\section{Priestly and Assyro-Babylonian Perspectives on Sin and its Consequences}

[Sühne und rituelle Reinigung. Priesterliche und assyrisch-babylonische Perspektiven auf Sünde und deren Konsequenzen.]

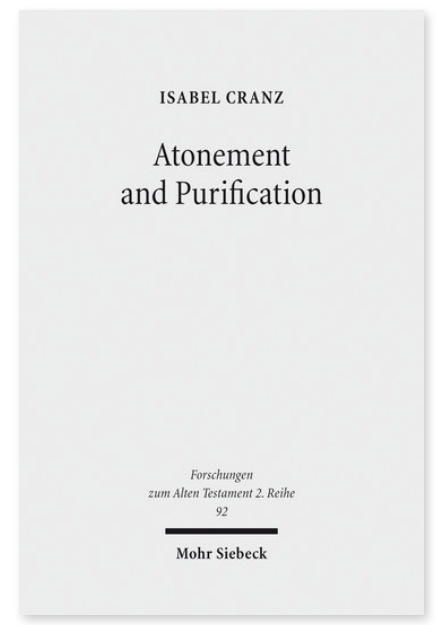

2017. XIII, 178 Seiten. FAT II 92

ISBN 978-3-16-155114-7

DOI 10.1628/978-3-16-155114-7

eBook PDF $69,00 €$

ISBN 978-3-16-154916-8

fadengeheftete Broschur $69,00 €$
Veröffentlicht auf Englisch.

Die alttestamentliche Forschung tendiert dazu, die priesterschriftlichen Rituale in den Kontext der Ritualtraditionen des Alten Orients zu stellen. Im Rahmen dieses Vergleiches wird der Priesterschrift (P) oftmals ein monotheistischer und polemisierender Charakter zugeschrieben. Isabel Cranz richtet dieses Verständnis der priesterschriftlichen Rituale neu aus, indem sie priesterschriftliche und assyro-babylonische Sühnerituale miteinander vergleicht. Dadurch wird gezeigt, dass die Rituale der Priesterschrift weitgehend auf die Aufrechterhaltung der göttlichen Präsenz im Heiligtum abzielen. Diese Einsicht lässt $P$ in einem neuen Licht erscheinen, da deutlich wird, dass diese Quelle kein Interesse daran hatte, monotheistische Vorstellungen durchzusetzen oder fremde Rituale abzuwerten. Stattdessen wollten die Verfasser der Priesterschrift bekräftigen, dass die Aaroniden als einzige priesterliche Gruppe für den Altardienst geeignet waren. Sollte P also eine Polemik enthalten, ist diese gegen die Gegner und Kritiker des aaronitischen Priestertums gerichtet und nicht gegen die Rituale des Alten Orients.

Isabel Cranz Born 1980; 2006 MA from Hebrew University (Rothberg); 2012 PhD from the Johns Hopkins University; since 2014 Assistant Professor of Hebrew Bible at the University of Pennsylvania.

\section{Jetzt bestellen:}

https://mohrsiebeck.com/buch/atonement-and-purification-9783161551147?no_cache=1 order@mohrsiebeck.com

Telefon: $+49(0) 7071-923-17$

Telefax: +49 (0)7071-51104 